\title{
Análise de componentes principais de atributos químicos e físicos do solo limitantes à produtividade de grãos
}

\author{
Antônio Luis Santi( ${ }^{(1)}$, Telmo Jorge Carneiro Amado(2), Maurício Roberto Cherubin(1), Thomas Newton Martin(2), \\ João Leonardo Pires ${ }^{(3)}$, Lisandra Pinto Della Flora ${ }^{(4)}$ e Claudir José Basso(1)
}

(1)Universidade Federal de Santa Maria, Centro de Educação Superior Norte do Rio Grande do Sul, Linha Sete de Setembro, BR 386, Km 40, CEP 98400-000 Frederico Westphalen, RS. E-mail: santi_pratica@yahoo.com.br, cherubin00@hotmail.com, claudirbasso@gmail.com (2)UFSM, Centro de Ciências Rurais, CEP 97105-900 Santa Maria, RS. E-mail: tamado@smail.ufsm.br, martin.ufsm@gmail.com (3)Empresa Brasileira de Pesquisa Agropecuária, Centro Nacional de Pesquisa de Trigo, Caixa Postal 45, CEP 99001-970 Passo Fundo, RS. E-mail: pires@cnpt.embrapa.br ${ }^{(4)}$ UFSM, Colégio Agrícola, Linha Sete de Setembro, BR 386, Km 40, CEP 98400-000 Frederico Westphalen, RS. E-mail: lisandra_cafw@yahoo.com.br

Resumo - O objetivo deste trabalho foi avaliar, por meio da análise dos componentes principais, a redução na dimensionalidade de atributos químicos e físicos do solo para a compreensão da variabilidade espacial e temporal da produtividade de culturas de grãos. A área experimental, de 54 ha, é manejada em agricultura de precisão há oito anos. Com base em seis mapas de colheita (soja - safra 2000/2001; milho - 2001/2002; soja - 2002/2003; trigo - 2003; soja - 2003/2004; e milho - 2004/2005), a área foi dividida em três zonas de produtividade de grãos (alta, média e baixa). Foram definidos 15 pontos georreferenciados representativos, para determinação de atributos químicos e físicos do solo, o que totalizou 63 variáveis analisadas. Entre os atributos químicos, o elevado teor de K no solo é o que melhor explica a variabilidade espacial da produtividade das culturas de grãos, provavelmente em razão do desbalanço das relações Ca:K e Mg:K. A zona de baixa produtividade apresentou baixa qualidade física do solo. Neste caso, a infiltração de água no solo, isoladamente, é a variável que melhor explica o desempenho das culturas de grãos. A análise dos componentes principais dos atributos químicos e físicos do solo é estratégia eficiente para explicar a variabilidade espacial e temporal da produtividade de culturas de grãos.

Termos para indexação: agricultura de precisão, análise multivariada, variabilidade espacial, variabilidade temporal, zonas de manejo.

\section{Principal component analysis of soil chemical and physical attributes limiting grain yield}

\begin{abstract}
The objective of this work was to evaluate, through principal component analysis, the reduction in the dimensionality of soil chemical and physical attributes in order to understand the spatial and temporal variability of grain crop yield. The experimental area of 54 ha has been managed under precision agriculture for eight years. Based on six grain yield maps (soybean - 2000/2001 harvest season; maize - 2001/2002; soybean -2002/2003; wheat - 2003; soybean - 2003/2004; and maize - 2004/2005), the area was split in three grain yield zones (high, medium, and low). Fifteen representative geo-referentiated points were defined in order to determine soil chemical and physical attributes, totaling 63 analyzed variables. Among chemical attributes, the high $\mathrm{K}$ content in soil is the variable that best explains the spatial variability of grain crop yield, probably due to the imbalance of the $\mathrm{Ca}: \mathrm{K}$ and $\mathrm{Mg}: \mathrm{K}$ relations. The low-yield zone had low soil physical quality. In this case, soil water infiltration, solely, is the variable that best explains the performance of the grain crops. Principal components analysis of soil chemical and physical attributes is an efficient strategy to explain the spatial and temporal variability of grain crop yield.
\end{abstract}

Index terms: precision agriculture, multivariate analysis, spatial variability, temporal variability, management zones.

\section{Introdução}

Um dos pressupostos básicos às técnicas de manejo sítio-específico adotadas na agricultura de precisão é o conhecimento da variabilidade dos atributos de solo e plantas, no espaço e no tempo (Mallarino \& Wittry, 2004; Grego \& Vieira, 2005). No entanto, para se conhecer a variabilidade espacial desses atributos adequadamente, é necessária a coleta de um grande conjunto de dados. 
A simples mensuração e a representação digital de um atributo isolado do solo, como resposta à prática de manejo, geralmente não são eficientes para estabelecer relação causa-efeito com a produtividade de culturas. Assim, muitos usuários da agricultura de precisão se frustram ao constatar que o mapa de prescrição de um nutriente, em taxa variada, por exemplo, o fósforo, não apresenta correspondência com o mapa de produtividade gerado após a intervenção. Em parte, isso se deve à complexidade do solo, que é considerado um sistema dinâmico cuja funcionalidade emerge de interações entre componentes físicos, químicos e biológicos (Vezzani \& Mielniczuk, 2009). Entretanto, as interações edafoclimáticas predominantes durante o ciclo da cultura aumentam a complexidade do entendimento dos fatores que governam o desempenho das culturas.

Estratégias de manejo e intervenções georreferenciadas exigem a compreensão de interações multidisciplinares, principalmente quando baseadas na relação de indicadores físico-químicos do solo com o desempenho das culturas avaliadas por meio de um conjunto de mapas de produtividade (Shiratsuchi et al., 2007). As ferramentas que auxiliam no processo incluem diversos procedimentos estatísticos (correlação simples, análise fatorial, análise dos componentes principais e análise dos fatores) que podem ser utilizados para investigar essas relações complexas (Shiratsuchi et al., 2007; Freddi et al., 2008; Nogara Neto et al., 2011).

Neste contexto, destaca-se o método da análise dos componentes principais (ACP), que consiste em reescrever as coordenadas das amostras em outro sistema mais conveniente para a análise de dados. Esse método permite a redução do número de variáveis avaliadas e pode ser usado para julgar a importância das próprias variáveis originais escolhidas, ou seja, aquelas que apresentam maior peso e são mais importantes do ponto de vista estatístico (Moita Neto \& Moita, 1998). Essa ferramenta pode auxiliar, também, na investigação de atributos físicos, químicos e mineralógicos de solos limitantes ao desenvolvimento vegetal (Gomes et al., 2004; Silva et al., 2010; Cherubin et al., 2011; Nogara Neto et al., 2011).

O objetivo deste trabalho foi avaliar, por meio da análise dos componentes principais, a redução na dimensionalidade de atributos químicos e físicos do solo para a compreensão da variabilidade espacial e temporal da produtividade de culturas de grãos.

\section{Material e Métodos}

A área experimental, com 57,4 ha, está localizada no Município de Palmeira das Missões, RS, entre as coordenadas UTM 262.517,3 (W) a 263.417,3 (W), e $6.919 .887(\mathrm{~S})$ a $6.919 .987(\mathrm{~S})$, fuso $22 \mathrm{Sul}$, na região do Planalto Médio. $\mathrm{O}$ solo pertence à unidade de mapeamento Passo Fundo e é classificado como Latossolo Vermelho distrófico típico, de textura argilosa (Santos et al., 2006). O relevo é suave ondulado, com altitude aproximada de $630 \mathrm{~m}$. O clima da região, segundo classificação de Maluf (2000), é subtropical, com primavera úmida, temperatura média anual de $18,1^{\circ} \mathrm{C}$ e precipitação pluvial anual de $1.919 \mathrm{~mm}$.

A área experimental vem sendo manejada sob sistema de semeadura direta há 15 anos, com cultivos rotacionados de soja e de milho no verão (soja 2000/2001; milho - 2001/2002; soja - 2002/2003; soja -2003/2004 e milho -2004/2005) e com trigo e culturas de cobertura hibernais (aveia-preta - 2000; nabo forrageiro-2001; trigo-2002; trigo-2003 e consórcio de aveia-preta, nabo-forrageiro e tremoço-azul-2004), de acordo com plano de rotação/sucessão de culturas pré-estabelecido. Após a cultura da aveia-preta (safra 2000), foi realizada calagem em superfície, na dose de $3 \mathrm{Mg} \mathrm{ha}^{-1}$ de calcário dolomítico.

Os dados de produtividade foram obtidos com o auxílio de colhedora Massey Ferguson, modelo MF 34, equipada com sistema "fieldstar", que congrega um conjunto composto de sensor de rendimento do tipo "micro-trak" de duas hastes, cartão para armazenamento de dados tipo PCMCIA e antena receptora de sinal com sistema de posicionamento global (GPS). O período de avaliação do desempenho das culturas foi de 2000 a 2004. No conjunto de dados de produtividade de grãos, foram considerados seis eventos de colheita (soja safra 2000/2001; milho-2001/2002; soja -2002/2003; trigo - 2003; soja - 2003/2004; e milho - 2004/2005). $\mathrm{Na}$ cultura de trigo (safra 2002), houve problema no armazenamento dos dados de produtividade e, por esta razão, essa safra foi desconsiderada.

$\mathrm{Na}$ área experimental, com base no histórico de produtividade de grãos, foram definidos 15 pontos georreferenciados, representativos de coleta de dados químicos e físicos do solo na área, o que totalizou 
63 variáveis analisadas. Para tanto, foram coletadas amostras de solo nas camadas de $0-0,05,0,05-0,10$ e $0,10-0,20 \mathrm{~m}$, com uso de pá de corte, conforme Comissão de Química e Fertilidade do Solo (2004). Os atributos químicos avaliados foram: $\mathrm{pH}$ em $\mathrm{H}_{2} \mathrm{O}$ (relação 1:1), índice SMP, teores de $\mathrm{P}$ e $\mathrm{K}$ extraídos por Mehlich-1 (relação 1:10), Al, Ca e Mg trocáveis, extraídos por $\mathrm{KCl} 1 \mathrm{~mol} \mathrm{~L}^{-1}$, e matéria orgânica determinada pelo método de combustão úmida. As determinações foram realizadas, segundo Tedesco et al. (1995), no Laboratório de Manejo e Conservação do Solo da Universidade Federal de Santa Maria, RS. Também foi determinado o teor de argila das amostras pelo método do densímetro (Tedesco et al., 1995). A partir desses dados, foi calculada a soma de bases, a CTC efetiva, a CTC em pH 7,0, a saturação por bases (V) e por $\mathrm{Al}(\mathrm{m})$, e as relações $\mathrm{Ca}: \mathrm{Mg}, \mathrm{K}: \mathrm{Mg}$ e $\mathrm{K}: \mathrm{Ca}$. Esses atributos foram submetidos à estatística descritiva, para verificar a posição (mínimo, médio, mediana e máximo) e a dispersão (desvio-padrão e coeficiente de variação) dos dados.

Para a avaliação da infiltração de água no solo, utilizaram-se dois métodos, com princípios de funcionamento diferentes: o método de duplos anéis concêntricos (método tradicional), descrito por Lanzanova et al. (2007), e o método de gotejamento "Cornell sprinkle infiltrometer", descrito por Es \& Schindelbeck (2003). Esse procedimento foi adotado porque o método de duplos anéis concêntricos tende a superestimar a infiltração (Santi et al., 2012) e não reproduz o processo de infiltração em áreas com declividade. Já o método de gotejamento, visa reproduzir as condições de infiltração de água no solo, na presença de chuvas simuladas (Santi et al., 2012), o que pode ser mais útil em áreas com maior declividade.

A estabilidade dos agregados em água foi avaliada na camada de 0-0,05 m, pelo método modificado de Kemper \& Chepil (1965), por meio de tamizamento via úmida, com uso de amostras de agregados que passaram por peneiras de $8 \mathrm{~mm}$ e ficaram retidos nas peneiras de $4,76 \mathrm{~mm}$. Foi avaliada a percentagem de agregados estáveis em cada classe $(8-4,7,4,76-2$, $2-1,1-0,21 \mathrm{e}<0,21 \mathrm{~mm})$. As avaliações da porosidade e da densidade do solo foram realizadas nas mesmas profundidades das análises químicas, de acordo com Blake \& Hartge (1986), com a utilização de anéis volumétricos de $3 \mathrm{~cm}$ de altura e $5,5 \mathrm{~cm}$ de diâmetro, saturados por 48 horas em bandeja com água até dois terços da altura do anel. Após o período de saturação, as amostras foram drenadas no potencial equivalente a -0,006 $\mathrm{MPa}$, sobre mesa de tensão. A resistência do solo à penetração foi avaliada a campo, sob condição de friabilidade $\left(0,27 \mathrm{~kg} \mathrm{~kg}^{-1}\right)$, até a profundidade de 0,50 m, com penetrômetro de impacto modelo IAA/ Planalsucar-Stolf, com cinco repetições por ponto. Os valores obtidos em $\mathrm{kgf} \mathrm{cm}^{-2}$ foram transformados em MPa.

As 63 variáveis, que compreenderam os atributos químicos e físicos do solo, foram previamente organizadas em planilha eletrônica Excel e, posteriormente, importadas para o programa CR-Campeiro7 (Giotto \& Robaina, 2007), para criação dos projetos digitais (integração do arquivo vetorial de contorno, arquivo vetorial de pontos amostrais e valor pontual das variáveis em estudo). Em seguida, foi realizada a estruturação dos modelos digitais de terreno (modelos matemáticos), com o ajuste dos modelos por parâmetros de grade, com pixels de $5 \times 5 \mathrm{~m}$, para que todos os modelos em análise tivessem o mesmo número de linhas e colunas correspondentes. Optou-se pela interpolação das variáveis por krigagem. Essas são rotinas padrões do programa CR-Campeiro7 que antecedem a visualização de mapas temáticos e, também, análises complementares de dados, como a ACP.

A partir dos 63 modelos digitais de terreno, com dimensões iguais e estruturados, foi calculada a correlação entre os modelos e elaboradas as matrizes de variância e covariância para proceder à ACP. Primeiramente, fez-se a ACP das 32 variáveis químicas do solo estudadas e, posteriormente, das 31 variáveis físicas do solo. Esses componentes foram construídos pela combinação da correlação entre as variáveis, sendo extraídas em ordem decrescente de importância, em termos de sua contribuição para a variação total dos dados (Silva et al., 2010). O critério para classificação dos autovetores (valores que representam o peso de cada caractere, em cada componente, e variam de -1 a +1$)$ foi: valor absoluto $<0,30$, classificado como pouco significativo; $0,30-0,40$, considerado mediamente significativo; $\mathrm{e} \geq 0,50$, tido como altamente significativo (Coelho, 2003). As variáveis químicas e físicas de solo que tiveram autovetores com peso $\geq 0,50$ (altamente significativo) foram submetidas a nova ACP, para ranquear o fator de solo com maior 
carga fatorial (escore), selecionado dentro do primeiro componente.

Para relacionar a produtividade com o fator de solo que apresentou maior carga fatorial, a área foi dividida em três zonas, de acordo com o histórico dos mapas de produtividade de grãos: produtividade de grãos real alta (PGRA), produtividade de grãos real média (PGRM) e produtividade de grãos real baixa (PGRB). Esta metodologia foi proposta por Molin (2002), em que os pontos de produtividade foram reduzidos para o mesmo número de pontos de atributos de solo analisados, com valor de produtividade média relativizada e com raio de $30 \mathrm{~m}$ ao redor do ponto georreferenciado de solo. A metodologia também estabelece classes de PGRB $<95 \%$, PGRM $=95-105 \%$ e PGRA $>105 \%$, dada a produtividade média obtida na respectiva safra. Para proceder a essa classificação, os dados de produtividade devem apresentar coeficiente de variação menor que $30 \%$.

\section{Resultados e Discussão}

O histórico de produtividade na área envolveu seis eventos de colheita de culturas de grãos. Para a cultura da soja, safra 2000/2001, o total de pontos armazenados e considerados na elaboração do mapa temático foi de 22.871. A PRGA foi de $4.860 \mathrm{~kg} \mathrm{ha}^{-1}$, a PRGM de $3.180 \mathrm{~kg} \mathrm{ha}^{-1}$ e a PRGB de $1.980 \mathrm{~kg} \mathrm{ha}^{-1}$, com desvio-padrão de $480 \mathrm{~kg}$ e coeficiente de variação (CV) de $16,20 \%$. Na safra 2002/2003, foram considerados 9.250 pontos, e a PRGA foi de $4.980 \mathrm{~kg} \mathrm{ha}^{-1}$, a PRGM de $3.240 \mathrm{~kg} \mathrm{ha}^{-1}$ e a PRGB de $1.800 \mathrm{~kg} \mathrm{ha}^{-1}$, com desvio-padrão de $1.800 \mathrm{~kg} \mathrm{ha}^{-1}$ e $\mathrm{CV}=20,62 \%$. Na safra 2003/2004, foram considerados 8.943 pontos, e a PRGA foi de $3.780 \mathrm{~kg} \mathrm{ha}^{-1}$, a PRGM de $2.220 \mathrm{~kg} \mathrm{ha}^{-1}$ e a PRGB de $720 \mathrm{~kg} \mathrm{ha}^{-1}$, com desvio-padrão de $600 \mathrm{~kg} \mathrm{ha}^{-1}$ e CV=18,73\%.

Estes resultados são indicativos de que houve variação espacial na produtividade de grãos na área experimental, porém com CV inferior a 30\%. Assim, a metodologia proposta (Molin, 2002) foi adequada para a definição das três zonas de produtividade e permitiu o avanço no estudo dos fatores condicionantes dessa variabilidade. As diferenças entre a maior e a menor produtividade de grãos de soja foram de 60,74 e $81 \%$, para as safras 2000/2001, 2002/2003 e 2003/2004, respectivamente, e revelaram importante variabilidade espacial. $\mathrm{O}$ acréscimo nas diferenças de produtividade entre as zonas, verificado na safra 2003/2004, pode ser justificado pelo estresse hídrico ocorrido no período coincidente com o desenvolvimento vegetativo e reprodutivo da cultura. Neste caso, a precipitação pluvial registrada para fevereiro de 2004 representou apenas 16\% (46 $\mathrm{mm})$ da precipitação ocorrida no mesmo período, em 2003 (284 mm). Já em 2005, esse índice foi ainda menor e representou 2,5\% (7 mm) do total precipitado em fevereiro de 2003 (284 mm). Para a cultura do milho, safra 2001/2002, o total de pontos armazenados e considerados na elaboração do mapa temático foi de 43.085, e a PRGA foi de $12.960 \mathrm{~kg} \mathrm{ha}^{-1}$, a PRGM de $7.800 \mathrm{~kg} \mathrm{ha}^{-1}$ e a PRGB de $3.060 \mathrm{~kg} \mathrm{ha}^{-1}$, com desvio-padrão de $1.620 \mathrm{~kg} \mathrm{ha}^{-1}$ e $\mathrm{CV}=20,80 \%$. $\mathrm{Na}$ safra 2003, de trigo, o número de pontos de colheita foi de 10.355 , a PRGA foi de $5.520 \mathrm{~kg} \mathrm{ha}^{-1}$, a PRGM de $3.540 \mathrm{~kg} \mathrm{ha}^{-1}$ e a PRGB de $960 \mathrm{~kg} \mathrm{ha}^{-1}$, com desvio-padrão de $660 \mathrm{~kg} \mathrm{ha}^{-1}$ e $\mathrm{CV}=18,18 \%$.

De modo geral, a área estudada apresentou solo com alta fertilidade, com exceção do $\mathrm{P}$, que se apresentou em níveis limitantes ao desenvolvimento de plantas, especialmente na camada mais profunda $(0,10-0,20 \mathrm{~m})$ (Tabela 1). Destaca-se que os teores de $\mathrm{Ca}, \mathrm{Mg}$ e $\mathrm{K}$ apresentaram níveis altos e muitos altos nas camadas superficiais (Comissão de Química e Fertilidade do Solo, 2004), e as suas relações (Ca:Mg, Ca:K e $\mathrm{Mg}: \mathrm{K})$ podem estar afetando a produtividade das culturas. Situações de manejo sob altas produtividades e presença de estiagem, solos com altos teores de K, concentrados nas camadas superficiais $(0-0,05$ ou 0-0,10 m), e a questão do desbalanço entre as relações $\mathrm{Ca}: \mathrm{Mg}, \mathrm{Ca}+\mathrm{Mg} / \mathrm{K}$ e $\mathrm{Mg} / \mathrm{K}$ devem ser melhor estudados e compreendidos (Shiratsuchi et al., 2007; Nogara Neto et al., 2011; Escosteguy, 2012). Em relação aos atributos físicos, o solo apresentou textura argilosa, com valores de densidades e resistência à penetração, nas camadas mais profundas, passíveis de causar limitação da infiltração de água e do desenvolvimento radicular das culturas (Tabela 2).

Os atributos químicos do solo (32 variáveis originais) foram agrupados em cinco fatores, e o ajuste do modelo foi capaz de explicar 99,24\% das variâncias das variáveis com autovalores maiores que 1 (Tabela 3). O primeiro componente explicou $53,83 \%$ da variabilidade química do solo da área experimental. Esse componente é constituído pelos teores de $\mathrm{P}$, nas camadas de $0,05-0,10$ e 0,10-0,20 $\mathrm{m}$, e de $\mathrm{K}$ nas camadas de $0-0,05$, 
$0,05-0,10,0,10-0,20$ e $0-0,10 \mathrm{~m}$, com escores positivos e altamente significativos. A proporção acumulada entre o primeiro e o segundo componente explicou $91,14 \%$ da variabilidade, e o teor de $K$, na camada de $0-0,05 \mathrm{~m}$, foi o caráter individual, com maior carga fatorial (escore), selecionado dentro do segundo fator, dentro do caractere principal $(0,836)$. É provável que os altos teores de $\mathrm{K}$, nessa camada $\left(336 \mathrm{mg} \mathrm{dm}^{-3}\right)$, mais de cinco vezes superior ao teor crítico $\left(60 \mathrm{mg} \mathrm{dm}^{-3}\right)$ estabelecido pela Comissão

Tabela 1. Análise estatística descritiva das variáveis químicas de um Latossolo Vermelho manejado com agricultura de precisão, em Palmeira das Missões, RS.

\begin{tabular}{|c|c|c|c|c|c|c|c|}
\hline Variáveis & Camada (m) & Mínimo & Média & Mediana & Máximo & $\mathrm{DP}^{(1)}$ & $\mathrm{CV}^{(2}$ \\
\hline $\mathrm{pH} \mathrm{em} \mathrm{H}_{2} \mathrm{O}$ & $0-0,05$ & 5,45 & 6,26 & 6,07 & 7,25 & 0,59 & 9,47 \\
\hline $\mathrm{pH} \mathrm{em} \mathrm{H}_{2} \mathrm{O}$ & $0,05-0,10$ & 5,29 & 6,16 & 6,15 & 6,95 & 0,55 & 8,95 \\
\hline $\mathrm{pH} \mathrm{em} \mathrm{H}_{2} \mathrm{O}$ & $0-0,10$ & 5,37 & 6,21 & 6,04 & 7,10 & 0,54 & 8,76 \\
\hline $\mathrm{pH}$ em $\mathrm{H}_{2} \mathrm{O}$ & $0,10-0,20$ & 4,98 & 5,90 & 5,76 & 6,86 & 0,57 & 9,73 \\
\hline Fósforo (mg dm $\left.{ }^{-3}\right)$ & $0-0,05$ & 2,50 & 7,03 & 5,50 & 17,50 & 4,02 & 57,13 \\
\hline Fósforo (mg dm $\left.{ }^{-3}\right)$ & $0,05-0,10$ & 2,50 & 5,56 & 4,80 & 15,80 & 3,99 & 71,70 \\
\hline Fósforo (mg dm-3) & $0-0,10$ & 3,20 & 6,30 & 5,15 & 16,65 & 3,69 & 58,57 \\
\hline Fósforo (mg dm ${ }^{-3}$ ) & $0,10-0,20$ & 1,50 & 2,96 & 2,50 & 4,80 & 0,94 & 31,71 \\
\hline Potássio $\left(\mathrm{mg} \mathrm{dm}^{-3}\right)$ & $0-0,05$ & 136,00 & 309,47 & 300,00 & 682,00 & 126,75 & 40,96 \\
\hline Potássio $\left(\mathrm{mg} \mathrm{dm}^{-3}\right)$ & $0,05-0,10$ & 52,00 & 131,60 & 134,00 & 242,00 & 47,57 & 36,15 \\
\hline Potássio $\left(\mathrm{mg} \mathrm{dm}^{-3}\right)$ & $0-0,10$ & 97,00 & 220,53 & 231,00 & 462,00 & 82,33 & 37,33 \\
\hline Potássio $\left(\mathrm{mg} \mathrm{dm}^{-3}\right)$ & $0,10-0,20$ & 28,00 & 72,27 & 64,00 & 148,00 & 38,76 & 53,63 \\
\hline Matéria orgânica (\%) & $0-0,05$ & 2,49 & 3,59 & 3,45 & 4,82 & 0,69 & 19,37 \\
\hline Matéria orgânica (\%) & $0,05-0,10$ & 2,28 & 2,95 & 2,90 & 3,50 & 0,34 & 11,58 \\
\hline Matéria orgânica (\%) & $0-0,10$ & 2,39 & 3,27 & 3,07 & 4,12 & 0,51 & 15,53 \\
\hline Matéria orgânica (\%) & $0,10-0,20$ & 2,04 & 2,67 & 2,73 & 3,10 & 0,33 & 12,42 \\
\hline Cálcio $\left(\mathrm{cmol}_{\mathrm{c}} \mathrm{dm}^{-3}\right)$ & $0-0,05$ & 5,45 & 8,07 & 7,77 & 10,96 & 1,84 & 22,82 \\
\hline Cálcio $\left(\mathrm{cmol}_{\mathrm{c}} \mathrm{dm}^{-3}\right)$ & $0,05-0,10$ & 4,51 & 7,11 & 6,96 & 9,90 & 1,71 & 23,99 \\
\hline Cálcio $\left(\mathrm{cmol}_{\mathrm{c}} \mathrm{dm}^{-3}\right)$ & $0-0,10$ & 5,09 & 7,59 & 6,96 & 9,93 & 1,71 & 22,50 \\
\hline Cálcio $\left(\mathrm{cmol}_{\mathrm{c}} \mathrm{dm}^{-3}\right)$ & $0,10-0,20$ & 2,28 & 5,63 & 5,75 & 7,84 & 1,48 & 26,32 \\
\hline Magnésio $\left(\mathrm{cmol}_{\mathrm{c}} \mathrm{dm}^{-3}\right)$ & $0-0,05$ & 2,43 & 3,69 & 3,72 & 4,99 & 0,71 & 19,29 \\
\hline Magnésio $\left(\mathrm{cmol}_{\mathrm{c}} \mathrm{dm}^{-3}\right)$ & $0,05-0,10$ & 2,20 & 3,25 & 3,25 & 4,15 & 0,62 & 19,21 \\
\hline Magnésio $\left(\mathrm{cmol}_{\mathrm{c}} \mathrm{dm}^{-3}\right)$ & $0-0,10$ & 2,31 & 3,47 & 3,52 & 4,37 & 0,63 & 18,19 \\
\hline Magnésio $\left(\mathrm{cmol}_{\mathrm{c}} \mathrm{dm}^{-3}\right)$ & $0,10-0,20$ & 1,18 & 2,73 & 2,68 & 3,79 & 0,69 & 25,34 \\
\hline $\mathrm{CTC}^{(3)}$ efetiva $\left(\mathrm{cmol}_{\mathrm{c}} \mathrm{dm}^{-3}\right)$ & $0-0,05$ & 8,98 & 12,56 & 12,28 & 17,69 & 2,66 & 21,14 \\
\hline CTC efetiva $\left(\mathrm{cmol}_{\mathrm{c}} \mathrm{dm}^{-3}\right)$ & $0,05-0,10$ & 7,04 & 10,72 & 10,62 & 14,38 & 2,31 & 21,54 \\
\hline CTC efetiva $\left(\mathrm{cmol}_{\mathrm{c}} \mathrm{dm}^{-3}\right)$ & $0-0,10$ & 8,04 & 11,64 & 11,27 & 15,42 & 2,38 & 20,42 \\
\hline CTC efetiva $\left(\mathrm{cmol}_{\mathrm{c}} \mathrm{dm}^{-3}\right)$ & $0,10-0,20$ & 5,44 & 8,75 & 8,95 & 11,88 & 1,85 & 21,10 \\
\hline Saturação por bases (\%) & $0-0,05$ & 72,13 & 83,63 & 85,51 & 90,97 & 5,27 & 6,30 \\
\hline Saturação por bases (\%) & $0,05-0,10$ & 57,06 & 78,48 & 77,63 & 88,78 & 8,94 & 11,39 \\
\hline Saturação por bases (\%) & $0-0,10$ & 65,15 & 81,32 & 82,65 & 89,65 & 6,74 & 8,29 \\
\hline Saturação por bases (\%) & $0,10-0,20$ & 45,94 & 70,66 & 73,71 & 82,97 & 11,94 & 16,90 \\
\hline Relação Ca:Mg & $0-0,05$ & 1,78 & 2,18 & 2,20 & 2,73 & 0,29 & 13,31 \\
\hline Relação Ca:Mg & $0,05-0,10$ & 1,89 & 2,17 & 2,18 & 2,58 & 0,24 & 11,02 \\
\hline Relação Ca:Mg & $0-0,10$ & 1,84 & 2,18 & 2,20 & 2,65 & 0,25 & 11,59 \\
\hline Relação Ca:Mg & $0,10-0,20$ & 1,86 & 2,05 & 2,02 & 2,33 & 0,14 & 6,76 \\
\hline Relação Ca:K & $0-0,05$ & 5,90 & 11,17 & 11,53 & 19,44 & 3,62 & 32,39 \\
\hline Relação Ca:K & $0,05-0,10$ & 13,16 & 23,14 & 21,14 & 39,70 & 7,69 & 33,22 \\
\hline Relação Ca:K & $0-0,10$ & 8,40 & 14,47 & 14,85 & 23,16 & 4,16 & 28,77 \\
\hline Relação Ca:K & $0,10-0,20$ & 14,64 & 36,84 & 34,72 & 65,95 & 15,57 & 42,28 \\
\hline Relação Mg:K & $0-0,05$ & 2,86 & 5,18 & 5,06 & 8,77 & 1,81 & 35,02 \\
\hline Relação Mg:K & $0,05-0,10$ & 5,73 & 10,56 & 10,71 & 18,90 & 3,74 & 34,80 \\
\hline Relação Mg:K & $0-0,10$ & 3,65 & 6,72 & 6,66 & 10,78 & 2,11 & 31,37 \\
\hline$\underline{\text { Relação Mg:K }}$ & $0,10-0,20$ & 6,45 & 18,09 & 16,37 & 31,16 & 7,78 & 42,99 \\
\hline
\end{tabular}

${ }^{(1)} \mathrm{DP}$, desvio-padrão. ${ }^{(2)}$ Coeficiente de variação $(\%) .{ }^{(3)} \mathrm{CTC}$, capacidade de troca de cátions. 
de Química e Fertilidade do Solo (2004), estejam promovendo alterações na absorção de $\mathrm{Ca}$ e $\mathrm{Mg}$ (Nogara Neto et al., 2011) ou mesmo favorecendo a lixiviação desses dois cátions no solo, em razão da competição por sítios do complexo de troca de cátions, o que justifica a inclusão dos atributos indicadores de acidez como o terceiro componente, capaz de explicar $96,49 \%$ da variabilidade.

Watanabe et al. (2005) verificaram que relações equilibradas dos elementos $\mathrm{Ca}, \mathrm{Mg}$ e $\mathrm{K}$, no complexo de troca, aumentaram a produtividade da cultura da soja de um Latossolo distroférrico no Paraná. Nogara Neto et al. (2011), ao avaliar a importância de atributos de solo na variação espacial de produtividade de grãos de milho, reportaram que o equilíbrio de bases foi importante para a nutrição de plantas de milho com reflexos na produtividade. Estes autores relataram a importância da relação $\mathrm{Mg}: \mathrm{K}$, com valor crítico de 2,30 , uma vez que a produtividade de milho decresceu quando os valores eram menores que este. Esses resultados corroboraram os de Shiratsuchi et al. (2007), que observaram que as zonas da área com melhores/ maiores relações $\mathrm{Ca}+\mathrm{Mg}: \mathrm{K}$ apresentaram as maiores produtividades de milho.

Quanto aos indicadores físicos, observou-se que a macroporosidade na camada de $0,05-0,10 \mathrm{~m}$; a infiltração de água no solo, investigada pelos métodos de duplos anéis concêntricos e pelo método "Cornell sprinkle infiltrometer"; a densidade do solo na camada de $0,10-0,20 \mathrm{~m}$; os agregados na classe $>4,76 \mathrm{~mm}$; e a resistência do solo à penetração, nas camadas de 0,25 $0,30,0,30-0,35,0,35-0,40,0,40-0,45$ e $0,45-0,50 \mathrm{~m}$,

Tabela 2. Análise estatística descritiva das variáveis físicas de um Latossolo Vermelho manejado com agricultura de precisão, em Palmeira das Missões, RS.

\begin{tabular}{|c|c|c|c|c|c|c|c|}
\hline Variáveis & Camada (m) & Mínimo & Mediana & Média & Máximo & $\mathrm{DP}^{(1)}$ & $\mathrm{CV}^{(2)}(\%)$ \\
\hline Argila (\%) & $0-0,05$ & 51,00 & 70,00 & 69,00 & 81,00 & 8,21 & 11,90 \\
\hline Argila (\%) & $0,05-0,10$ & 50,00 & 77,00 & 74,60 & 88,00 & 10,13 & 13,58 \\
\hline Argila (\%) & $0,10-0,20$ & 67,00 & 79,00 & 78,60 & 90,00 & 7,26 & 9,23 \\
\hline Microporosidade $\left(\mathrm{cm} \mathrm{cm}^{-3}\right)$ & $0-0,05$ & 0,40 & 0,44 & 0,44 & 0,49 & 0,03 & 6,04 \\
\hline Microporosidade $\left(\mathrm{cm} \mathrm{cm}^{-3}\right)$ & $0,05-0,10$ & 0,43 & 0,47 & 0,47 & 0,52 & 0,02 & 5,16 \\
\hline Microporosidade $\left(\mathrm{cm} \mathrm{cm}^{-3}\right)$ & $0,10-0,20$ & 0,40 & 0,46 & 0,46 & 0,51 & 0,03 & 5,84 \\
\hline Macroporosidade $\left(\mathrm{cm} \mathrm{cm}^{-3}\right)$ & $0-0,05$ & 0,09 & 0,17 & 0,16 & 0,19 & 0,03 & 20,13 \\
\hline Macroporosidade $\left(\mathrm{cm} \mathrm{cm}^{-3}\right)$ & $0,05-0,10$ & 0,07 & 0,12 & 0,12 & 0,18 & 0,03 & 25,65 \\
\hline Macroporosidade $\left(\mathrm{cm} \mathrm{cm}^{-3}\right)$ & $0,10-0,20$ & 0,04 & 0,13 & 0,13 & 0,17 & 0,04 & 28,93 \\
\hline Porosidade total $\left(\mathrm{cm} \mathrm{cm}^{-3}\right)$ & $0-0,05$ & 0,54 & 0,61 & 0,60 & 0,66 & 0,03 & 4,91 \\
\hline Porosidade total $\left(\mathrm{cm} \mathrm{cm}^{-3}\right)$ & $0,05-0,10$ & 0,52 & 0,58 & 0,58 & 0,64 & 0,03 & 5,31 \\
\hline Porosidade total $\left(\mathrm{cm} \mathrm{cm}^{-3}\right)$ & $0,10-0,20$ & 0,54 & 0,58 & 0,58 & 0,65 & 0,03 & 5,17 \\
\hline Densidade $\left(\mathrm{g} \mathrm{cm}^{-3}\right)$ & $0-0,05$ & 1,25 & 1,37 & 1,37 & 1,49 & 0,08 & 5,56 \\
\hline Densidade $\left(\mathrm{g} \mathrm{cm}^{-3}\right)$ & $0,05-0,10$ & 1,39 & 1,50 & 1,50 & 1,59 & 0,07 & 4,43 \\
\hline Densidade $\left(\mathrm{g} \mathrm{cm}^{-3}\right)$ & $0,10-0,20$ & 1,35 & 1,49 & 1,50 & 1,66 & 0,07 & 4,91 \\
\hline Agregados $>4,76(\%)$ & $0-0,05$ & 3,06 & 39,06 & 36,21 & 60,02 & 16,58 & 45,77 \\
\hline Agregados 4,76-2,0 (\%) & $0-0,05$ & 6,31 & 21,52 & 20,19 & 33,62 & 6,95 & 34,40 \\
\hline Agregados $2,0-1,0(\%)$ & $0-0,05$ & 6,98 & 11,63 & 11,98 & 19,37 & 3,81 & 31,79 \\
\hline Agregados $1,0-0,21(\%)$ & $0-0,05$ & 7,16 & 19,06 & 18,65 & 37,41 & 8,21 & 44,02 \\
\hline Agregados $<0,21(\%)$ & $0-0,05$ & 2,03 & 10,24 & 12,96 & 56,52 & 14,46 & 57,56 \\
\hline Infiltração Cornell $\left(\mathrm{mm} \mathrm{h}^{-1}\right)$ & - & 176,00 & 312,00 & 306,00 & 418,00 & 90,57 & 29,60 \\
\hline Infiltração duplos anéis concêntricos $\left(\mathrm{mm} \mathrm{h}^{-1}\right)$ & - & 52,00 & 243,00 & 248,53 & 427,00 & 109,73 & 44,15 \\
\hline Resistência à penetração (MPa) & $0,05-0,10$ & 1,19 & 1,69 & 1,68 & 2,08 & 0,29 & 17,56 \\
\hline Resistência à penetração $(\mathrm{MPa})$ & $0,10-0,15$ & 1,24 & 2,35 & 2,32 & 3,41 & 0,68 & 29,34 \\
\hline Resistência à penetração (MPa) & $0,15-0,20$ & 2,81 & 4,13 & 4,19 & 6,06 & 0,95 & 22,60 \\
\hline Resistência à penetração (MPa) & $0,20-0,25$ & 4,07 & 4,99 & 5,28 & 6,90 & 0,96 & 18,16 \\
\hline Resistência à penetração (MPa) & $0,25-0,30$ & 3,22 & 4,95 & 4,92 & 6,59 & 1,19 & 24,10 \\
\hline Resistência à penetração (MPa) & $0,30-0,35$ & 3,19 & 4,52 & 4,53 & 6,14 & 1,00 & 22,08 \\
\hline Resistência à penetração (MPa) & $0,35-0,40$ & 2,93 & 4,18 & 4,18 & 5,79 & 0,90 & 21,45 \\
\hline Resistência à penetração (MPa) & $0,40-0,45$ & 2,87 & 4,05 & 4,12 & 5,18 & 0,82 & 19,97 \\
\hline Resistência à penetração (MPa) & $0,45-0,50$ & 3,18 & 4,18 & 4,24 & 5,21 & 0,71 & 16,75 \\
\hline
\end{tabular}

${ }^{(1)} \mathrm{DP}$, desvio-padrão. ${ }^{(2)}$ Coeficiente de variação (\%). 
explicaram $88,71 \%$ do primeiro componente principal (Tabela 4).

A infiltração de água, independentemente do método utilizado, foi o caráter individual mais importante, tendo sido positivo e de maior peso. Os componentes principais 1 e 2 , juntos, explicaram $98,65 \%$ da variabilidade, com acréscimo de $9,94 \%$ na proporção acumulada. A microporosidade, na camada 0,05-0,10 $\mathrm{m}$, e a resistência do solo à penetração, na camada de $0,15-0,20$ e $0,20-0,25 \mathrm{~m}$, atingiram valores superiores ao escore $0,500(-0,518,-0,610$ e $-0,507$, respectivamente). Esses atributos tiveram escores negativos e altamente significativos. Nicoloso et al. (2008), ao investigar atributos de um Latossolo sob sistema de plantio direto, reportaram relação inversa entre macroporosidade e resistência do solo, bem como entre resistência do solo e infiltração de

Tabela 3. Análise de componentes principais das variáveis químicas de um Latossolo Vermelho manejado com agricultura de precisão, em Palmeira das Missões, RS.

\begin{tabular}{|c|c|c|c|c|c|}
\hline \multirow{2}{*}{ Componentes da variância } & \multicolumn{5}{|c|}{ Componentes principais } \\
\hline & 1 & 2 & 3 & 4 & 5 \\
\hline Autovalores & $5.721,10$ & $3.965,00$ & 568,30 & 177,60 & 114,59 \\
\hline Proporção (\%) & 53,83 & 37,31 & 5,35 & 1,67 & 1,08 \\
\hline Proporção acumulada (\%) & 53,83 & 91,14 & 96,49 & 98,16 & 99,24 \\
\hline Variáveis & \multicolumn{5}{|c|}{ Correlação com os componentes principais } \\
\hline $\mathrm{pH}$ em $\mathrm{H}_{2} \mathrm{O}(0-0,10 \mathrm{~m})$ & $-0,050$ & $-0,082$ & $0,759^{(1)}$ & $-0,538^{(1)}$ & $-0,083$ \\
\hline $\mathrm{pH}$ em $\mathrm{H}_{2} \mathrm{O}(0-0,05 \mathrm{~m})$ & 0,105 & $-0,002$ & $0,717^{(1)}$ & $-0,533^{(1)}$ & $-0,077$ \\
\hline $\mathrm{pH}$ em $\mathrm{H}_{2} \mathrm{O}(0,05-0,10 \mathrm{~m})$ & $-0,186$ & $-0,168$ & $0,770^{(1)}$ & $-0,451$ & $-0,046$ \\
\hline $\mathrm{pH}$ em $\mathrm{H}_{2} \mathrm{O}(0,10-0,20 \mathrm{~m})$ & $-0,086$ & 0,074 & $0,772^{(1)}$ & $-0,157$ & 0,481 \\
\hline Fósforo $(0-0,10 \mathrm{~m})$ & 0,409 & $-0,037$ & 0,040 & $0,705^{(1)}$ & 0,049 \\
\hline Fósforo $(0-0,05 \mathrm{~m})$ & $-0,295$ & 0,045 & 0,453 & 0,253 & 0,249 \\
\hline Fósforo $(0,05-0,10 \mathrm{~m})$ & $0,560^{(1)}$ & $-0,069$ & $-0,162$ & $0,633^{(1)}$ & $-0,079$ \\
\hline Fósforo $(0,10-0,20 \mathrm{~m})$ & $0,518^{(1)}$ & 0,000 & $-0,146$ & $0,697^{(1)}$ & $-0,054$ \\
\hline Potássio $(0-0,10 \mathrm{~m})$ & $0,969^{(1)}$ & 0,219 & $-0,101$ & $-0,043$ & 0,019 \\
\hline Potássio $(0-0,05 \mathrm{~m})$ & $0,548^{(1)}$ & $0,836^{(1)}$ & 0,006 & $-0,005$ & $-0,003$ \\
\hline Potássio $(0,05-0,10 \mathrm{~m})$ & $0,793^{(1)}$ & $-0,587$ & $-0,150$ & $-0,056$ & 0,030 \\
\hline Potássio $(0,10-0,20 \mathrm{~m})$ & $0,818^{(1)}$ & $-0,399$ & 0,387 & 0,123 & $-0,068$ \\
\hline Matéria orgânica $(0-0,10$ m) & 0,106 & 0,197 & $-0,177$ & 0,427 & 0,154 \\
\hline Matéria orgânica $(0-0,05$ m) & 0,168 & 0,169 & $-0,088$ & 0,403 & 0,149 \\
\hline Matéria orgânica $(0,05-0,10 \mathrm{~m})$ & $-0,031$ & 0,240 & $-0,348$ & 0,446 & 0,161 \\
\hline Matéria orgânica $(0,10-0,20$ m) & $-0,048$ & $-0,092$ & $-0,330$ & 0,263 & 0,253 \\
\hline Cálcio $(0-0,10 \mathrm{~m})$ & 0,382 & 0,045 & $0,685^{(1)}$ & $-0,241$ & $-0,159$ \\
\hline Cálcio (0-0,05 m) & 0,375 & 0,017 & $0,611^{(1)}$ & $-0,265$ & $-0,334$ \\
\hline Cálcio $(0,05-0,10$ m) & 0,359 & 0,077 & $0,724^{(1)}$ & $-0,189$ & 0,084 \\
\hline Cálcio $(0,10-0,20$ m) & $-0,118$ & 0,300 & 0,215 & 0,387 & $0,654^{(1)}$ \\
\hline Magnésio (0-0,10 m) & 0,025 & $-0,088$ & $0,868^{(1)}$ & $-0,220$ & $-0,056$ \\
\hline Magnésio (0-0,05 m) & 0,023 & 0,009 & $0,740^{(1)}$ & $-0,136$ & $-0,316$ \\
\hline Magnésio $(0,05-0,10 \mathrm{~m})$ & 0,016 & $-0,160$ & $0,832^{(1)}$ & $-0,251$ & 0,199 \\
\hline Magnésio $(0,10-0,20$ m) & $-0,315$ & 0,308 & $0,687^{(1)}$ & $-0,350$ & 0,488 \\
\hline $\mathrm{CTC}^{(2)}$ efetiva $(0-0,10 \mathrm{~m})$ & 0,326 & 0,004 & $0,757^{(1)}$ & $-0,241$ & $-0,138$ \\
\hline CTC efetiva $(0-0,05 \mathrm{~m})$ & 0,323 & 0,024 & $0,677^{(1)}$ & $-0,210$ & $-0,310$ \\
\hline CTC efetiva $(0,05-0,10 \mathrm{~m})$ & 0,325 & $-0,073$ & $0,776^{(1)}$ & $-0,237$ & 0,146 \\
\hline CTC efetiva $(0,10-0,20 \mathrm{~m})$ & $-0,206$ & 0,318 & 0,361 & 0,216 & $0,666^{(1)}$ \\
\hline Saturação por bases $(0-0,10 \mathrm{~m})$ & $-0,036$ & $-0,054$ & $0,786^{(1)}$ & $-0,581^{(1)}$ & $-0,108$ \\
\hline Saturação por bases $(0-0,05 \mathrm{~m})$ & 0,074 & 0,006 & $0,724^{(1)}$ & $-0,571^{(1)}$ & $-0,218$ \\
\hline Saturação por bases $(0,05-0,10 \mathrm{~m})$ & $-0,093$ & $-0,110$ & $0,796^{(1)}$ & $-0,528^{(1)}$ & 0,044 \\
\hline Saturação por bases $(0,10-0,20 \mathrm{~m})$ & 0,038 & 0,074 & $0,598^{(1)}$ & 0,104 & $0,788^{(1)}$ \\
\hline
\end{tabular}

${ }^{(1)}$ Caracteres com maiores cargas fatoriais (escores) selecionadas dentro de cada fator. O critério para classificação foi: valor absoluto <0,30, considerado pouco significativo; 0,30-0,40, mediamente significativo; e $\geq 0,50$, altamente significativo, de acordo com Coelho (2003). ${ }^{(2)} \mathrm{CTC}$, capacidade de troca de cátions. 
água, e relação positiva entre macroporosidade, na camada superficial, e infiltração de água.

O teor de argila no solo, nas camadas de $0,05-0,10$ e $0,10-0,20 \mathrm{~m}$, e a proporção de macroagregados $(>4,76 \mathrm{~mm})$ foram os caracteres que melhor explicaram o componente principal 3, com escores na ordem de 0,844, 0,788 e -0,691, respectivamente. Embora a proporção de microagregados $(<0,21 \mathrm{~mm})$ não tenha sido considerada na discussão do componente 1 , esta apresentou escore de $-0,493$ e foi classificada como mediamente significativa. Esses dados, cumulativamente, mostram que os componentes 1, 2 e 3 explicaram $99,38 \%$ da variabilidade existente (Tabela 4), o que está de acordo com Amado et al. (2007b).

A infiltração de água no solo, investigada pelos métodos de duplos anéis concêntricos e "Cornell sprinkle infiltrometer", apresentou os maiores escores $(0,938$ e 0,937 , respectivamente), o que confirma que a baixa qualidade física do solo, expressa pelos atributos físico-hídricos, caracterizou-se como a principal limitação à expressão do potencial produtivo

Tabela 4. Análise de componentes principais das variáveis físicas de um Latossolo Vermelho manejado com agricultura de precisão, em Palmeira das Missões, RS.

\begin{tabular}{|c|c|c|c|c|c|}
\hline \multirow{2}{*}{ Componentes da variância } & \multicolumn{5}{|c|}{ Componentes principais } \\
\hline & 1 & 2 & 3 & 4 & 5 \\
\hline Autovalores & $18.251,70$ & $2.645,70$ & 150,60 & 51,30 & 46,69 \\
\hline Proporção (\%) & 88,71 & 9,94 & 0,73 & 0,25 & 0,23 \\
\hline Proporção acumulada (\%) & 88,71 & 98,65 & 99,38 & 99,63 & 99,86 \\
\hline Variáveis & \multicolumn{5}{|c|}{ Correlação com os componentes principais } \\
\hline Argila $(0-0,05 \mathrm{~m})$ & $-0,300$ & $-0,062$ & $0,511^{(1)}$ & $0,750^{(1)}$ & 0,284 \\
\hline Argila $(0,05-0,10 \mathrm{~m})$ & $-0,410$ & $-0,046$ & $0,844^{(1)}$ & $-0,112$ & $-0,263$ \\
\hline Argila $(0,10-0,20 \mathrm{~m})$ & 0,360 & $-0,053$ & $0,788^{(1)}$ & $-0,080$ & $-0,194$ \\
\hline Microporosidade $(0-0,05 \mathrm{~m})$ & $-0,387$ & $-0,183$ & 0,072 & 0,228 & $-0,468$ \\
\hline Microporosidade $(0,05-0,10 \mathrm{~m})$ & $-0,030$ & $-0,518^{(1)}$ & 0,241 & $-0,061$ & $-0,526^{(1)}$ \\
\hline Microporosidade $(0,10-0,20 \mathrm{~m})$ & 0,057 & $-0,389$ & 0,494 & 0,108 & $-0,328$ \\
\hline Macroporosidade $(0-0,05 \mathrm{~m})$ & $-0,014$ & 0,146 & $-0,047$ & 0,271 & 0,041 \\
\hline Macroporosidade $(0,05-0,10 \mathrm{~m})$ & $-0,830^{(1)}$ & $-0,082$ & 0,119 & $0,554^{(1)}$ & 0,215 \\
\hline Macroporosidade $(0,10-0,20 \mathrm{~m})$ & $-0,442$ & 0,350 & $-0,076$ & 0,234 & 0,244 \\
\hline Porosidade total $(0-0,05 \mathrm{~m})$ & $-0,299$ & $-0,006$ & $-0,046$ & 0,494 & $-0,322$ \\
\hline Porosidade total $(0,05-0,10 \mathrm{~m})$ & $-0,145$ & $-0,481$ & 0,287 & 0,432 & $-0,231$ \\
\hline Porosidade total $(0,10-0,20 \mathrm{~m})$ & $-0,451$ & 0,049 & 0,400 & 0,361 & 0,015 \\
\hline Densidade $(0-0,05 \mathrm{~m})$ & 0,006 & $-0,062$ & $0,549^{(1)}$ & $-0,101$ & 0,328 \\
\hline Densidade $(0,05-0,10 \mathrm{~m})$ & 0,230 & $-0,185$ & 0,193 & $-0,067$ & 0,286 \\
\hline Densidade $(0,10-0,20 \mathrm{~m})$ & $0,538^{(1)}$ & $-0,454$ & 0,418 & 0,100 & $-0,124$ \\
\hline Agregados $>4,76(0-0,05 \mathrm{~m})$ & $0,521^{(1)}$ & 0,156 & $-0,691^{(1)}$ & 0,161 & $-0,213$ \\
\hline Agregados 4,76-2,0 (0-0,05 m) & $-0,036$ & $-0,406$ & 0,208 & 0,438 & $-0,430$ \\
\hline Agregados 2,0-1,0 (0-0,05 m) & 0,143 & $-0,038$ & 0,256 & $-0,127$ & $-0,409$ \\
\hline Agregados $1,0-0,21(0-0,05 \mathrm{~m})$ & $-0,310$ & $-0,354$ & 0,319 & 0,429 & $-0,423$ \\
\hline Agregados $<0,21(0-0,05 \mathrm{~m})$ & $-0,493$ & 0,111 & 0,410 & $-0,378$ & $0,656^{(1)}$ \\
\hline Infiltração Cornell & $0,920^{(1)}$ & 0,392 & 0,004 & 0,001 & 0,000 \\
\hline Infiltração duplos anéis concêntricos & $0,967^{(1)}$ & $-0,254$ & 0,002 & $-0,001$ & 0,002 \\
\hline Resistência à penetração $(0,05-0,10$ m) & $-0,336$ & $-0,359$ & $-0,044$ & $-0,110$ & $-0,331$ \\
\hline Resistência à penetração $(0,10-0,15$ m) & 0,463 & $-0,457$ & 0,321 & $-0,530^{(1)}$ & $-0,215$ \\
\hline Resistência à penetração $(0,15-0,20$ m) & 0,388 & $-0,610^{(1)}$ & 0,195 & 0,108 & $-0,243$ \\
\hline Resistência à penetração $(0,20-0,25$ m) & $-0,410$ & $-0,507^{(1)}$ & $-0,232$ & 0,059 & $-0,259$ \\
\hline Resistência à penetração $(0,25-0,30$ m) & $-0,708^{(1)}$ & $-0,286$ & $-0,237$ & $-0,131$ & $-0,152$ \\
\hline Resistência à penetração $(0,30-0,35$ m) & $-0,623^{(1)}$ & $-0,352$ & $-0,309$ & $-0,188$ & $-0,148$ \\
\hline Resistência à penetração $(0,35-0,40$ m) & $-0,562^{(1)}$ & $-0,265$ & $-0,408$ & $-0,189$ & $-0,224$ \\
\hline Resistência à penetração $(0,40-0,45$ m) & $-0,623^{(1)}$ & $-0,221$ & $-0,367$ & $-0,123$ & $-0,248$ \\
\hline Resistência à penetração $(0,45-0,50$ m) & $-0,653^{(1)}$ & $-0,226$ & $-0,364$ & $-0,096$ & $-0,224$ \\
\hline
\end{tabular}

${ }^{(1)}$ Caracteres com maiores cargas fatoriais (escores) selecionadas dentro de cada fator. O critério para classificação foi: valor absoluto <0,30, considerado pouco significativo; 0,30-0,40, mediamente significativo; e $\geq 0,50$, altamente significativo, de acordo com Coelho (2003). 
das culturas nessa área não irrigada (Tabela 5). A infiltração de água é considerada um atributo que integra várias propriedades físico-hídricas do solo e indica a qualidade do solo (Amado et al., 2007a; Vezzani \& Mielniczuk, 2009). A resistência do solo à penetração, abaixo da camada de $0,25 \mathrm{~m}$, apresentou valores negativos, o que é indicativo de provável impedimento físico ao crescimento radicular, a partir dessa camada. Esses caracteres, em conjunto com a densidade do solo $(0,10-0,20 \mathrm{~m})$, a proporção de macroagregados $(>4,76 \mathrm{~mm})$ e os teores de $\mathrm{K}$ no solo, nas camadas de $0-0,10$ e $0,10-0,20 \mathrm{~m}$, representaram 64,19\% da informação estatística no componente 1.

Embora a infiltração de água esteja entre as variáveis com maior escore, somente quando se acumulou o segundo e o terceiro componentes é que foi possível explicar 94,93\% da variabilidade observada na área. $\mathrm{O}$ teor de $\mathrm{K}$ no solo foi a variável que explicou as proporções nos componentes 2 e 3 , e, independentemente da camada analisada, os valores ficaram acima do nível estabelecido como crítico, ou seja, acima de $60 \mathrm{mg} \mathrm{kg}^{-1}$. Dessa forma, para minimizar possíveis desequilíbrios nutricionais e limitações físico-hídricas na área, torna-se necessária a adoção de práticas de manejo que conduzam a uma maior infiltração de água e ao equilíbrio de bases no complexo de troca, especialmente na camada superficial.

Tanto para a cultura da soja quanto para a do milho, produtividades de grãos acima de $90 \%$ foram alcançadas quando a taxa de infiltração de água foi superior a $400 \mathrm{~mm}$ (Figura 1). Nicoloso et al. (2008) observaram maior produtividade de soja e trigo com o incremento da infiltração de água. Apesar de relatos de que a infiltração de água no solo apresenta alta variabilidade espacial (Vieira et al., 2010; Santi et al., 2012), verificou-se que, como as zonas homogêneas são estabelecidas com base nos mapas de produtividade acumulada, as propriedades hidrodinâmicas do solo não foram distribuídas espacialmente de modo desordenado, mas apresentaram certa estruturação em zonas de manejo (Figura 2).

A infiltração de água no solo, determinada pelo método de duplos anéis concêntricos, apresentou relação linear direta com as zonas de alta, média e baixa produtividade relativa de grãos real, com coeficiente de determinação de 0,71 , para as culturas da soja e do

Tabela 5. Análise dos componentes principais que apresentaram escore $\geq 0,500$ (positiva ou negativa) com os componentes principais 1 e 2.

\begin{tabular}{|c|c|c|c|c|c|}
\hline \multirow{2}{*}{ Componentes da variância } & \multicolumn{5}{|c|}{ Componentes principais } \\
\hline & 1 & 2 & 3 & 4 & 5 \\
\hline Autovalores & $20.083,20$ & $5.504,80$ & $4.113,30$ & 770,00 & 388,20 \\
\hline Proporção (\%) & 64,19 & 17,59 & 13,15 & 2,46 & 1,24 \\
\hline Proporção acumulada (\%) & 64,19 & 81,78 & 94,93 & 97,39 & 98,63 \\
\hline Variáveis & \multicolumn{5}{|c|}{ Correlação com os componentes principais } \\
\hline Fósforo $(0,05-0,10 \mathrm{~m})$ & 0,337 & 0,233 & 0,385 & $-0,015$ & 0,091 \\
\hline Fósforo $(0,10-0,20 \mathrm{~m})$ & 0,415 & 0,230 & 0,258 & 0,020 & 0,096 \\
\hline Potássio $(0-0,10 \mathrm{~m})$ & $0,519^{(1)}$ & $0,677^{(1)}$ & 0,488 & $-0,175$ & $-0,059$ \\
\hline Potássio $(0-0,05 \mathrm{~m})$ & 0,288 & $0,915^{(1)}$ & $-0,181$ & $-0,211$ & 0,048 \\
\hline Potássio $(0,05-0,10 \mathrm{~m})$ & 0,430 & $-0,019$ & $0,891^{(1)}$ & $-0,023$ & $-0,136$ \\
\hline Potássio $(0,10-0,20 \mathrm{~m})$ & $0,559^{(1)}$ & 0,112 & $0,711^{(1)}$ & 0,168 & 0,353 \\
\hline Macroporosidade $(0,05-0,10 \mathrm{~m})$ & $-0,140$ & $-0,255$ & $-0,185$ & 0,118 & $-0,422$ \\
\hline Densidade $(0,10-0,20 \mathrm{~m})$ & $0,515^{(1)}$ & $-0,458$ & 0,135 & $-0,155$ & 0,000 \\
\hline Agregados $>4,76(0-0,05 \mathrm{~m})$ & $0,536^{(1)}$ & 0,060 & 0,100 & 0,065 & $-0,356$ \\
\hline Agregados $<0,21(0-0,05 \mathrm{~m})$ & $-0,487$ & 0,259 & $-0,203$ & $-0,154$ & 0,111 \\
\hline Infiltração Cornell & $0,937^{(1)}$ & 0,241 & $-0,147$ & 0,199 & $-0,046$ \\
\hline Infiltração duplos anéis concêntricos & $0,938^{(1)}$ & $-0,315$ & $-0,078$ & $-0,120$ & 0,018 \\
\hline Resistência à penetração $(0,25-0,30 \mathrm{~m})$ & $-0,724^{(1)}$ & $-0,120$ & 0,061 & $-0,325$ & $-0,339$ \\
\hline Resistência à penetração $(0,30-0,35 \mathrm{~m})$ & $-0,652^{(1)}$ & $-0,181$ & $-0,011$ & $-0,379$ & $-0,350$ \\
\hline Resistência à penetração $(0,35-0,40 \mathrm{~m})$ & $-0,573^{(1)}$ & $-0,157$ & 0,124 & $-0,233$ & $-0,465$ \\
\hline Resistência à penetração $(0,40-0,45 \mathrm{~m})$ & $-0,635^{(1)}$ & $-0,180$ & 0,146 & $-0,088$ & $-0,448$ \\
\hline Resistência à penetração $(0,45-0,50 \mathrm{~m})$ & $-0,660^{(1)}$ & $-0,130$ & 0,152 & $-0,175$ & $-0,354$ \\
\hline
\end{tabular}

Pesq. agropec. bras., Brasília, v.47, n.9, p.1346-1357, set. 2012 
milho (Figura 1). Embora a infiltração avaliada com infiltrômetros não possa ser diretamente comparada com a precipitação, principalmente se a intensidade desta variar ao longo do tempo (Lima \& Silans, 1999), a avaliação das relações entre a infiltração de água no solo com a produtividade das culturas permite, em condições de lavoura, selecionar as práticas de manejo a serem adotadas para o estabelecimento de porosidade contínua, equilíbrio entre macro e microporosidade (Lanzanova et al., 2010), aumento da estabilidade de agregados (Wendling et al., 2005) e, consequentemente, maior volume de água disponível (Amado et al., 2009). Matzenauer et al. (2003) demostraram que, no Rio Grande do Sul, em 9 de 20 anos, há probabilidade de ocorrer redução de produtividade de grãos de soja, associado ao deficit hídrico. Portanto, neste cenário, a qualidade física do solo passa a ter papel preponderante no desempenho das culturas de grãos.

Apesar de os valores de infiltração acumulada de água, de 200 e 400 mm, não poderem ser generalizados para outros tipos de solo ou ser usados como um índice para definir zonas de PGRB e PGRA, eles podem ser indicativos importantes para novos estudos e para compreender as razões da variabilidade espacial da produtividade em áreas agrícolas.

Os resultados apresentados no presente trabalho estão de acordo com os de Montezano et al. (2006). Estes autores verificaram que, em escala de campo, as correlações lineares dos atributos de fertilidade com a produtividade geralmente são baixos (menores que

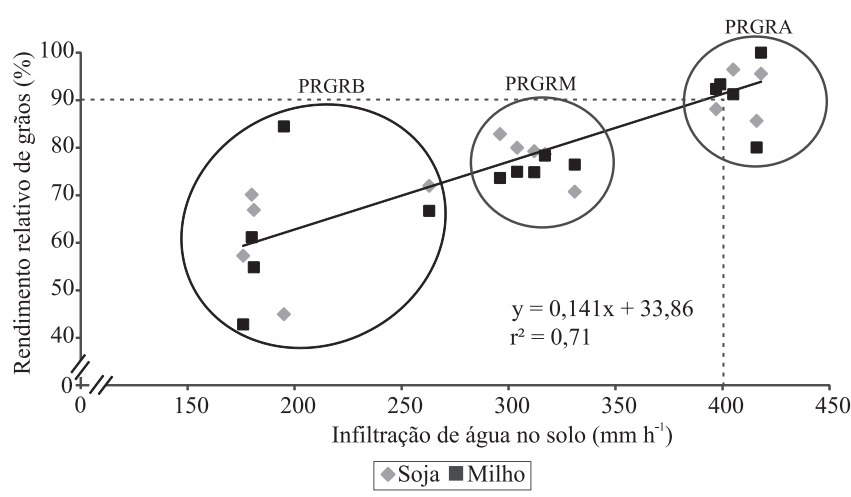

Figura 1. Relação de infiltração acumulada de água, em um Latossolo Vermelho, avaliada pelo método de duplos anéis concêntricos, para as culturas do milho (safra 2002/2003) e da soja (safra 2003/2004), em anos de disponibilidade hídrica adequada, em cada zona de produtividade de grãos real alta (PGRA), média (PGRM) e baixa (PGRB).

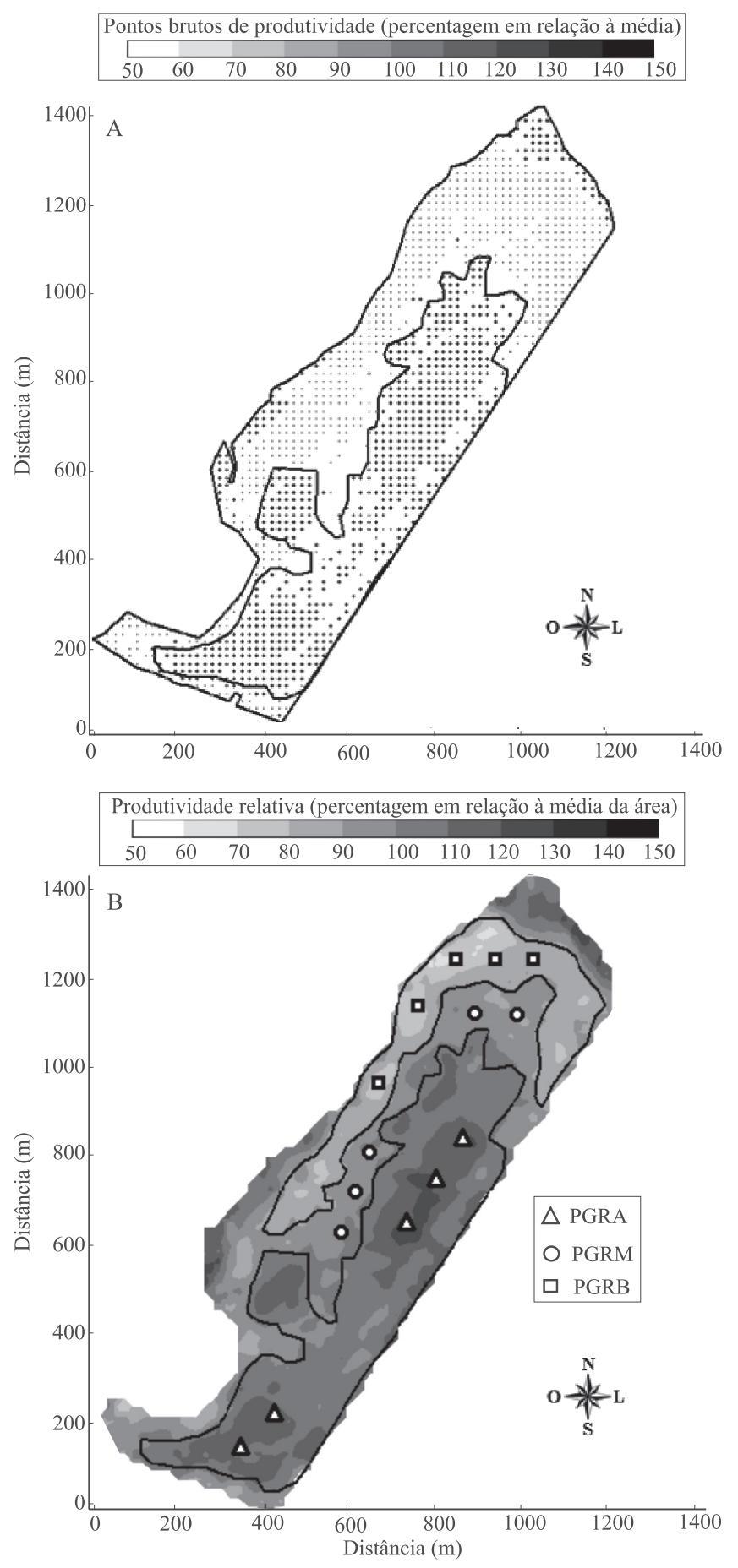

Figura 2. Mapa temático com a distribuição dos pontos amostrais de alta e baixa produtividade em relação à média (A) e produtividade relativa interpolada por krigagem, com seis eventos de colheita sobrepostos (soja - 2000/2001; milho - 2001/2002; soja - 2002/2003; trigo - 2003; soja - 2003/2004 e milho - 2004/2005) (B). Delimitação, em ambos os mapas, das zonas de produtividade de grãos real alta (PRGA), produtividade de grãos real média (PGRM) e produtividade de grãos real baixa (PGRB). 
0,50), o que impede isolar fatores bióticos e abióticos que influenciam a produção da cultura. $\mathrm{Na}$ agricultura de precisão, dificilmente uma única variável conseguirá explicar, isoladamente, a variabilidade espacial da produtividade de grãos em culturas anuais, como soja, milho e trigo. O cruzamento de variáveis físicas e químicas é importante, uma vez que a alteração, em uma variável, pelo manejo do solo, acaba modificando outras variáveis. Neste caso, o uso da técnica da redução de variáveis é importante para selecionar os principais componentes, para identificar e interpretar a distribuição das variáveis originais de maior peso.

\section{Conclusões}

1. A análise de componentes principais dos atributos químicos e físicos do solo é estratégia eficiente para explicar a variabilidade espacial e temporal da produtividade de culturas de grãos em área cultivada há oito anos sob manejo sítio-especifico do solo.

2. Entre as variáveis químicas e físicas avaliadas, o desbalanço de bases e a limitação da infiltração de água no solo, respectivamente, são as que mais frequentemente limitam a produtividade de grãos.

\section{Agradecimentos}

À Fundação Agrisus - Agricultura Sustentável, pelo apoio financeiro e pela concessão de bolsa; e ao Dr. Enio Giotto, pelas sugestões e pela colaboração nas análises.

\section{Referências}

AMADO, T.J.C.; CONCEIÇÃO, P.C.; BAYER, C.; ELTZ, F.L.F. Qualidade do solo avaliada pelo "Soil Quality Kit Test" em dois experimentos de longa duração no Rio Grande do Sul. Revista Brasileira de Ciência do Solo, v.31, p.109-121, 2007a.

AMADO, T.J.C.; PES, L.Z.; LEMAINSKI, C.L.; SCHENATO, R.B. Atributos químicos e físicos de latossolos e sua relação com os rendimentos de milho e feijão irrigados. Revista Brasileira de Ciência do Solo, v.33, p.831-843, 2009.

AMADO, T.J.C.; PONTELlI, C.B.; SANTI, A.L.; VIANA, J.H.M.; SULZBACH, L.A. de S. Variabilidade espacial e temporal da produtividade de culturas sob sistema plantio direto. Pesquisa Agropecuária Brasileira, v.42, p.1101-1110, $2007 \mathrm{~b}$.

BLAKE, G.R.; HARTEGE, K.H. Bulk density. In: KLUTE, A. (Ed.). Methods of soil analysis: physical and mineralogical methods. Madison: American Society of Agronomy, 1986. p.363-375. (ASA. Agronomy, 9).
CHERUBIN, M.R.; SANTI, A.L.; BASSO, C.J.; EITELWEIN, M.T.; VIAN, A.L. Caracterização e estratégias de manejo da variabilidade espacial dos atributos químicos do solo utilizando a análise dos componentes principais. Enciclopédia Biosfera, v.7, p.196-210, 2011.

COELHO, A.M. Agricultura de precisão: manejo da variabilidade espacial e temporal dos solos e das culturas. In: CURI, N.; MARQUES, J.J.; GUILHERME, L.R.G.; LIMA, J.M. de; LOPES, A.S.; ALVARES V., V.H. (Ed.). Tópicos em ciência do solo. Viçosa: Sociedade Brasileira de Ciência do Solo, 2003. v.3, p.259-290.

COMISSÃO DE QUÍMICA E FERTILIDADE DO SOLO. Manual de adubação e de calagem para os Estados do Rio Grande do Sul e Santa Catarina. 10.ed. Porto Alegre: Sociedade Brasileira de Ciência do Solo - Núcleo Regional Sul, 2004. 400p.

ES, H. van; SCHINDELBECK, R. Field procedures and data analysis for the Cornell Sprinkle Infiltrometer. 2003. Available at: <www.sjrcd.org/soilhealth/healthysoil/staff-infiltrometer.pdf>. Accessed on: 23 Oct. 2012.

ESCOSTEGUY, P.A.V. Deficiência de potássio em lavouras de soja do Planalto do Rio Grande do Sul. Revista Plantio Direto, n.127, p.1-16, 2012.

FREDDI, O. da S.; FERRAUDO, A.S.; CENTURION, J.F. Análise multivariada na compactação de um Latossolo Vermelho cultivado com milho. Revista Brasileira de Ciência do Solo, v.32, p.953-961, 2008.

GIOTTO, E.; ROBAINA, A.D. A agricultura de precisão com o CR Campeiro 7: manual do usuário. Santa Maria: UFSM, 2007. 319p.

GOMES, J.B.V.; CURI, N.; MOTTA, P.E.F.; KER, J.C.; MARQUES, J.J.G.S.M.; SCHULZE, D.G. Análise de componentes principais de atributos físicos, químicos e mineralógicos de solos do bioma cerrado. Revista Brasileira de Ciência do Solo, v.28, p.137-153, 2004

GREGO, C.R.; VIEIRA, S.R. Variabilidade espacial de propriedades físicas do solo em uma parcela experimental. Revista Brasileira de Ciência do Solo, v.29, p.169-177, 2005.

KEMPER, W.D.; CHEPIL, W.S. Size distribution of aggregates. In: BLACK, C.A.; EVANS, D.D.; WHITE, J.L.; ENSMINGER, L.E.; CLARK, F.E. (Ed.). Methods of soil analysis. Part 1. Physical and mineralogical properties, including statistics of measurement and sampling. Madison: American Society of Agronomy, 1965. p.499-510.

LANZANOVA, M.E.; ELTZ, F.L.F.; NICOLOSO, R. da S.; AMADO, T.J.C.; REINERT, D.J.; ROCHA, M.R. da. Atributos físicos de um Argissolo em sistemas de culturas de longa duração sob semeadura direta. Revista Brasileira de Ciência do Solo, v.34, p.1333-1342, 2010.

LANZANOVA, M.E.; NICOLOSO, R. da S.; LOVATO, T.; ELTZ, F.L.F.; AMADO, T.J.C.; REINERT, D.J. Atributos físicos do solo em sistema de integração lavoura-pecuária sob plantio direto. Revista Brasileira de Ciência do Solo, v.31, p.1131-1140, 2007.

LIMA, C.A.G.; SILANS, A.P. de. Variabilidade espacial da infiltração de água no solo. Pesquisa Agropecuária Brasileira, v.34, p.2311-2320, 1999. 
MALLARINO, A.P.; WITTRY, D. Efficacy of grid and zone soil sampling approaches for site-specific assessment of phosphorus, potassium, $\mathrm{pH}$, and organic matter. Precision Agriculture, v.5, p.131-144, 2004.

MALUF, J.R.T. Nova classificação climática do Estado do Rio Grande do Sul. Revista Brasileira de Agrometeorologia, v.8, p.141-150, 2000.

MATZENAUER, R.; BARNI, N.A.; MALUF, J.R.T. Estimativa do consumo relativo de água para a cultura da soja no Estado do Rio Grande do Sul. Ciência Rural, v.33, p.1013-1019, 2003.

MOITA NETO, J.M.; MOITA, G.C. Uma introdução à análise exploratória de dados multivariados. Química Nova, v.21, p.467-469, 1998.

MOLIN, J.P. Definição de unidades de manejo a partir de mapas de produtividade. Engenharia Agrícola, v.22, p.83-92, 2002.

MONTEZANO, Z.F.; CORAZZA, E.J.; MURAOKA, T. Variabilidade espacial da fertilidade do solo em área cultivada e manejada homogeneamente. Revista Brasileira de Ciência do Solo, v.30, p.839-847, 2006.

NICOLOSO, R. da S.; AMADO, T.J.C.; SCHNEIDER, S.; LANZANOVA, M.E.; GIRARDELLO, V.C.; BRAGAGNOLO, J. Eficiência da escarificação mecânica e biológica na melhoria dos atributos físicos de um Latossolo muito Argiloso e no incremento do rendimento de soja. Revista Brasileira de Ciência do Solo, v.32, p.1723-1734, 2008.

NOGARA NETO, F.; ROLOFF, G.; DIECKOW, J.; MOTTA, A.C.V. Atributos de solo e cultura espacialmente distribuídos relacionados ao rendimento do milho. Revista Brasileira de Ciência do Solo, v.35, p.1025-1036, 2011.

SANTI, A.L.; AMADO, T.J.C.; SILVA, V.R. da; BASSO, C.J.; DELLA FLORA, L.P.; CHERUBIN, M.R.; EITELWEIN, M.T. Infiltração de água no solo, determinada por diferentes métodos, como indicador do potencial produtivo em dois Latossolos manejados com agricultura de precisão. Interciencia, v.37, p.204-208, 2012.
SANTOS, H.G. dos; JACOMINE, P.K.T.; ANJOS, L.H.C. dos; OLIVEIRA, V.A. de; OLIVEIRA, J.B. de; COELHO, M.R.; LUMBRERAS, J.F.; CUNHA, T.J.F. (Ed.). Sistema brasileiro de classificação de solos. 2.ed. Rio de Janeiro: Embrapa Solos, 2006. $306 \mathrm{p}$.

SHIRATSUCHI, L.S.; MARCHÃO, R.L.; JERKE, C.; RESENDE, A.V.; FONTES, J.R.A.; OLIVEIRA, C.M. de; VILELA, M. de F.; SÁ, M.A.C. de; SANTOS JÚNIOR, J. de D.G. dos; HURTADO, S.M.C. Geração de mapas multitemáticos em agricultura de precisão. Planaltina: Embrapa Cerrados, 2007. 22p. (Embrapa Cerrados. Boletim de pesquisa e desenvolvimento, 181).

SILVA, S. de A.; LIMA, J.S. de S.; XAVIER, A.C.; TEIXEIRA, M.M. Variabilidade espacial de atributos químicos de um Latossolo Vermelho-Amarelo húmico cultivado com café. Revista Brasileira de Ciência do Solo, v.34, p.15-22, 2010.

TEDESCO, M.J.; GIANELLO, C.; BISSANI, C.A.; BOHNEN, H.; VOLKWEISS, S.J. Análise de solo, plantas e outros materiais. 2.ed. rev. amp. Porto Alegre: Universidade Federal do Rio Grande do Sul, 1995. 174p. (UFRGS. Boletim técnico, 5).

VEZZANI, F.M.; MIELNICZUK, J. Uma visão sobre qualidade do solo. Revista Brasileira de Ciência do Solo, v.33, p.743-755, 2009.

VIEIRA, S.R.; BRANCALIÃO, S.R.; GREGO, C.R.; MARTINS, A.L.M. Variabilidade espacial de atributos físicos de um Argissolo Vermelho-Amarelo cultivado com leguminosas consorciada com a seringueira. Bragantia, v.69, p.423-432, 2010.

WATANABE, R.T.; FIORETTO, R.A.; FONSECA, I.B. da; SEIFERT, A.L.; SANTIAGO, D.C.; CRESTE, J.E.; HARADA, A.; CUCOLOTTO, M. Produtividade da cultura de soja em função da densidade populacional e da porcentagem de cátions ( $\mathrm{Ca}, \mathrm{Mg}$ e K) no complexo sortivo do solo. Semina: Ciências Agrárias, v.26, p.477-484, 2005.

WENDLING, B.; JUCKSCH, I.; MENDONÇA, E. de S.; NEVES, J.C.L. Carbono orgânico e estabilidade de agregados de um Latossolo Vermelho sob diferentes manejos. Pesquisa Agropecuária Brasileira, v.40, p.487-494, 2005.

Recebido em 31 de julho de 2011 e aprovado em 22 de agosto de 2012

Pesq. agropec. bras., Brasília, v.47, n.9, p.1346-1357, set. 2012 